\title{
A vulneração socioambiental advinda do complexo industrial portuário de Suape: a perspectiva dos moradores da Ilha de Tatuoca - Ipojuca/PE
}

The socio-environmental vulnerability resulting from the industrial complex port of suape: the perspective of the residents of the Tatuoca Island-Ipojuca/PE

La vulneración socio ambiental advenida del complejo industrial portuario de Suape: la perspectiva de los habitantes de la Isla de Tatuoca - Ipojuca-PE

Renata Cordeiro DOMINGUES ${ }^{1}$

Mariana Olivia Santana dos SANTOS ${ }^{2}$ Idê Gomes Dantas GURGEL ${ }^{3}$

\section{RESUMO}

A comunidade tradicional de pescadores artesanais da Ilha de Tatuoca enfrenta intensos conflitos socioambientais, decorrentes das obras de expansão do Complexo Industrial e Portuário de Suape, em Pernambuco. Nos últimos anos, esses conflitos materializam-se em um profundo processo de desterritorialização das famílias e em uma evidente descaracterização da Ilha de Tatuoca, considerada Área de Preservação Permanente (APP). Diante disso, este estudo se preocupa em compreender a percepção e os aspectos subjetivos da população exposta aos conflitos socioambientais, presentes no território. Para tanto, esta pesquisa objetiva analisar o discurso dos moradores da Ilha de Tatuoca sobre o processo de vulneração socioambiental ativo no local.

Palavras-chave: saúde ambiental; vulnerabilidade social; meio ambiente; saúde pública; impacto ambiental

ABSTRACT

The community of traditional artisanal fishermen Tatuoca Island faces intense socioenvironmental conflicts, following the expansion of the Industrial and Port Complex of Suape

1 Enfermeira, mestranda em Saúde Pública pelo Centro de Pesquisa Aggeu Magalhães - Fiocruz/PE. E-mail: renatinhadomingues@gmail.com

2 Bacharel em Comunicação Social pela Universidade Federal de Pernambuco, Especialista e mestra em Saúde Pública pelo CpqAM. Doutoranda em Saúde Pública pelo Centro de Pesquisa Aggeu Magalhães/Fiocruz/MS. E-mail: marianaxolivia@gmail.com

3 Graduada em Medicina pela Universidade Federal da Paraíba, Mestre e Doutora em Saúde Pública pelo CPqAM/ FIOCRUZ. E-mail: ideg@cpqam.fiocruz.br 
facilities, in the State of Pernambuco, Brazil. In recent years, these conflicts materialize in a profound process of de-territorialization of households and an evident mischaracterization of the Tatuoca Island, considered a Permanent Preservation Areas (APP). Thus, this study seeks to understand the perception and the subjective aspects of the exposed population over the territory under conflict. Therefore, this research aims to analyze the speech of the inhabitants of the Tatuoca Island about the process of socio-environmental vulnerability in this setting.

Key words: environmental health; social vulnerability; environment; public health; environmental impact

\section{RESUMEN}

La comunidad tradicional de pescadores artesanales de la Isla de Tatuoca enfrenta intensos conflictos socio ambientales, derivados de las obras de expansión del Complejo Industrial y Portuario de Suape, en el Estado de Pernambuco, Brasil. En los últimos años estos conflictos se materializan en un profundo proceso de desterritorialización de las familias y en evidente descaracterización de la Isla de Tatuoca, considerada área de Preservación Permanente (APP). Delante de eso, este estudio se preocupa en comprender la percepción y los aspectos subjetivos de la población expuesta a los conflictos ambientales, presentes en el territorio. Así, esta investigación objetiva analizar el discurso de los habitantes de la Isla de Tatuoca en el proceso de activa vulneración socio ambiental en el lugar.

Palabras claves: salud ambiental; vulnerabilidad social; medio ambiente; salud pública, impacto ambiental

\section{INTRODUÇÃO}

Desde o final da década de 1970 a saúde coletiva ultradimensiona a perspectiva e seus objetos de estudo, a partir da ampliação do conceito de saúde, que se fundamenta na determinação social da saúde e nas condições de vida e de cidadania dos sujeitos. Conforme assinala Buss:

A saúde é produto de um amplo espectro de fatores relacionados com a qualidade de vida, incluindo um padrão adequado de alimentação e nutrição, e de habitação e saneamento; boas condições de trabalho; oportunidades de educação ao longo de toda a vida; ambiente físico limpo; apoio social para famílias e indivíduos; estilo de vida responsável; e um espectro adequado de cuidados de saúde. ${ }^{1}$

A possibilidade de transmutar o pensamento clássico da saúde, biologicista e reduzido, para uma esfera ampliada - que abraça o processo de determinação social da saúde - torna-se viável à medida que se compreende a articulação existente entre as desigualdades sociais e a saúde com o processo de adoecimento das populações humanas. Sob a luz de uma perspectiva ampliada, a saúde 
é compreendida, sobretudo, como um fenômeno essencialmente humano e não somente enquanto um fato biológico natural. ${ }^{2}$

A discussão sobre o processo de determinação social da saúde é bastante relevante por construir um novo modelo que reorienta a práxis da saúde e suas teorias. Em sua dimensão epistemológica, se faz necessário diferenciar, claramente, a definição de determinantes sociais da saúde do conceito de determinação social da saúde. O primeiro limita-se a descrever a saúde e a doença por meio do "emprego de esquemas de causalidade, que realizam uma associação empiricista entre condições de saúde e fatores sociais". ${ }^{2}$ O segundo explica a saúde como um fenômeno processual, emergido socialmente de uma "complexidade histórica concreta." Dessa forma, aqui comporta uma analogia, com fim de esclarecimento, que observa os determinantes sociais da saúde como pontos isolados, que através de várias possibilidades e formas se interrelacionam e tecem uma rede complexa e processual, aqui chamada de determinação social da saúde.

Além desse aspecto, é importante ressaltar que a perspectiva ampliada de saúde reconhece a natureza política do processo de determinação social da saúde. Diante disso, Boaventura de Sousa Santos $^{3}$ atenta para o ressurgimento de antigas formas de colonialismo, ajustadas para as sociedades democráticas, cujos governos se eximem da regulação estatal e privatizam os serviços públicos. Dessa forma, impetuosos atores não estatais apropriam-se do poder e do controle sobre as vidas e o bem estar de vastas populações, por meio da aquisição do "controle sobre os cuidados de saúde, da terra, da água potável, das sementes, das florestas ou da qualidade ambiental."”

A área de conhecimento da saúde coletiva dedica-se ao estudo desses processos e recentemente incorpora discussões sobre a bioética da proteção, que ganha relevância através das discussões e análises sobre a responsabilidade do Estado em regular as dinâmicas discriminatórias do uso do poder e que sobrecarregam populações vulneradas. A bioética da proteção preocupa-se ainda em, cuidadosamente, desconstruir a sutil e importante confusão realizada entre os conceitos de vulnerabilidade e de vulneração.

Vulnerabilidade se refere à condição de quem pode ser ferido (ou traumatizado), ao passo que vulneração se refere especificamente à condição de quem já está ferido (ou traumatizado). Dito de forma mais geral, no primeiro caso estamos em presença de uma potencialidade compartilhada pelo universo de todos os seres vivos. No segundo, de algo em ato em determinados seres vivos específicos e que é necessariamente universalizável, pois todos os seres vivos são por essência vulneráveis devido à condição de finitude e mortalidade que os caracteriza, ao passo que somente alguns são de fato afetados ou vulnerados. ${ }^{4}$

A vulneração, portanto, é pautada nesse estudo como a nuance que permite dar luz e precisão ao reconhecimento de povos e comunidades que se encontram em processo ativo de violência e discriminação. Porto ${ }^{5}$ comenta que as comunidades de povos tradicionais são atingidas pelos grandes empreendimentos, por meio de concessões estatais fomentadas por poderosas coalizões, 
que percebem esses povos como arcaicos obstáculos ao progresso. A saúde coletiva possibilita a investigação desses conflitos com a finalidade de fortalecer suas bases e proporcionar a criação de práticas contra-hegemônicas, que disparem processos de mudança e se mantenham alinhadas com os princípios de liberdade, democracia, qualidade de vida e bem viver.

Historicamente, as regiões do Norte e Nordeste brasileiros apresentam os piores índices de desenvolvimento social e de qualidade de vida. Tal condição revela as precárias estruturas de vida e saúde das populações, fomentada por um processo histórico de desigualdade social e exploração territorial em regiões de pobreza.

O estado de Pernambuco, localizado na região do Nordeste brasileiro, segue apresentando destaque progressivo no cenário econômico nacional, devido à presença de intensos processos de industrialização tardia e urbanização desordenada, pela implamentação de grandes empreendimentos como a transposição das águas do Rio São Francisco - no Sertão, implantação de um polo farmacoquímico - no Norte do estado, e o Projeto do Complexo Industrial de Suape (CIPS) - no litoral Sul.

Neste contexto, é de suma importância o desenvolvimento de estudos, sob a perspectiva da saúde coletiva, que analisem os impactos de grandes empreendimentos e processos produtivos no ambiente e na saúde das populações humanas. Dessa forma, este estudo tem o objetivo de analisar o discurso dos moradores da Ilha de Tatuoca em relação ao processo de vulneração sociambiental presente no território em conflito.

\section{Suape: território de conflitos e injustiças ambientais}

Desde sua elaboração na década de 1970, o CIPS prevê a instalação de mais de 130 indústrias, entre elas: uma refinaria de petróleo, um polo petroquímico, três estaleiros, um complexo de fertilizantes, uma fábrica de alumínio, uma de cimento e uma de pneumáticos. O projeto mantevese estagnado, durante um largo intervalo de tempo, e apenas na última década foi retomada sua implementação com o Programa de Aceleração do Crescimento (PAC), que propunha gerar riqueza e desenvolvimento para o estado, empregos para a população local, assim como melhorias nas condições de vida.

A forma como grande parte dos empreendimentos deste programa está sendo implementada nos cenários locais parece revelar projetos desarticulados, sob a perspectiva da produção de resultado econômico em curto prazo. ${ }^{6}$ Essa qualidade compromete o crescimento da economia com equidade social e aproxima o PAC de políticas desenvolvimentistas que contradizem os fundamentos do desenvolvimento sustentável.

O Território Estratégico de Suape (TES) compreende os municípios do Cabo de Santo Agostinho, Ipojuca, Jaboatão dos Guararapes, Moreno, Escada, Ribeirão, Sirinhaém e Rio Formoso. A adoção 
do termo gestor Território Estrátégico de Suape deve-se à compreensão de que o lugar é favorável à implementação de políticas estaduais de desenvolvimento portuário e industrial. ${ }^{7} \mathrm{O}$ TES encontrase interligado a mais de 160 portos presentes em todos os continentes, em estreita proximidade à capital pernambucana, e apresenta forte centralidade em relação à região Nordeste, oferecendo abundância de recursos naturais, necessários ao processo de industrialização. ${ }^{8}$ Abrange parte do litoral Sul da região metropolitana de Recife, assim como grandes latifúndios que compreendem terras de 22 antigos engenhos de cana de açúcar, atividade econômica historicamente presente na região. O caráter misto litorâneo/rural da região favorece a instalação de grandes indústrias com cadeias produtivas extrativistas e de forte impacto socioambiental.

A situação de vulneração socioambiental amplia-se e complexifica-se quando, ao analisar com cuidado a totalidade da implementacão do projeto do CIPS, percebe-se que os impactos socioambientais se encontram ativos, desde o princípio das obras de construção de suas indústrias, a exemplo da Petroquímica, dos Estaleiros e Refinaria Abreu e Lima (RNEST). Intervenções de alto impacto ambiental como as dragagens alteram a profundidade, salinidade e curso dos rios, além de alterar a dinâmica natural dos mangues e ecossistemas locais. Dessa forma, o caráter labiríntico dos impactos e múltiplo dos processos de determinação social da saúde revela a necessidade de uma abordagem própria aos sistemas complexos. ${ }^{9}$

Este cenário ilustra a realidade vivida por uma comunidade tradicional de pescadores artesanais, localizada na Ilha de Tatuoca, que atualmente enfrenta intensos conflitos socioambientais por se encontrar situada na região de expansão do CIPS. Essa comunidade vem sendo progressivamente desterritorializada, a partir de processos atropelados pela dinâmica do crescimento econômico do estado, e o ambiente natural segue sofrendo profundas modificações em suas características originais.

A instalação e operação de grandes processos produtivos industriais apresentam nexos causais com problemas de ordem socioambiental e de saúde das áreas e populações direta e indiretamente afetadas. Os problemas derivam de conflitos ambientais decorrentes de disputas entre os interesses das comunidades locais e grupos sociais organizados, pautados pela premissa da justiça ambiental, e grandes corporações beneficiadas por atividades econômicas. ${ }^{5}$

$\mathrm{Na}$ atual conjuntura do capitalismo globalizado, os conflitos socioambientais emergem de um mercado de caráter internacional injusto e insustentável, que se fundamentam na divisão internacional do trabalho e dos riscos que sobrecarregam países, territórios e populações vulneráveis. ${ }^{10}$

O conceito de justiça ambiental é entendido como um conjunto de princípios e práticas sociais que asseguram a qualquer grupo social de natureza diversa a proteção de seus direitos, frente às consequências negativas de dinâmicas e ações de finalidade econômica. ${ }^{11}$ Porto ${ }^{11}$ comenta ainda que a justiça ambiental "busca assegurar tanto o acesso justo e equitativo aos recursos ambientais do país quanto o acesso amplo às informações relevantes ao conjunto da sociedade e grupos afetados". 
O problema aqui exposto apresenta, enquanto núcleo de discussão, as implicações materiais e imateriais, vinculadas ao processo de expropriação territorial dessas famílias e à injustiça ambiental. Pois, existe a compreensão que todo terrritório "é ao mesmo tempo e obrigatoriamente, em diferentes combinações, funcional e simbólico, pois as relações de poder têm no espaço um componente indissociável tanto na realização de 'funções' quanto na produção de 'significados"”. ${ }^{12}$ Porto $^{5}$ comenta que "o território é pleno de lutas, de cultura, de formas próprias de organização social, institucional, de economia e memória."

A geografia crítica explica os processos de Territorialização-DesterritorializaçãoReterritorialização (TDR) como um continuum inacabado. ${ }^{12}{ }^{13}$ Dessa forma, o processo de desterritorialização, não se esgota em si e se apresenta sequenciado de uma reterritorialização em níveis variados. Ainda neste contexto, a dimensões materiais envolvidas nos processos de TDR relacionam-se mais diretamente a precariedade das questões de infraestrutura, mais evidentes nos primeiros anos de reassentamento, associadas à fragilidade de políticas públicas de compensação. Já no que se refere às dimensões imateriais, destacam-se aqui os aspectos culturais, de identidade territorial, dentre os quais se sobressaem os sentimentos de saudosismo entre os familiares dispersos no processo, sensações de estranhamento do novo lugar, isolamento geográfico, entre outros. ${ }^{12}$

A apropriação do espaço e o desenvolvimento de afeto por ele são elementos que favorecem a construção de um conhecimento tradicional. A Política Nacional de Desenvolvimento Sustentável dos Povos e Comunidades Tradicionais, instituída através do Decreto n ${ }^{\circ} 6040$ sancionado em 2007 , define esses povos e comunidades como:

Grupos culturalmente diferenciados e que se reconhecem como tais, que possuem formas próprias de organização social, que ocupam e usam territórios e recursos naturais como condição para sua reprodução cultural, social, religiosa, ancestral e econômica, utilizando conhecimentos, inovações e práticas gerados e transmitidos pela tradição. ${ }^{14}$

Enfatiza-se os atributos e qualidades próprios de grupos particulares,

"que permitam diferenciar os povos e comunidades tradicionais do restante da sociedade, clarificando assim quais princípios poderiam servir como elementos identificadores desse conjunto heterogêneo" ${ }^{\prime 5}$.

A elaboração e a legitimação de um conceito permite maiores possibilidades de se retirar as diferenças da penumbra da invisibilidade e fortalecer as condições de operacionalização de políticas que assegurem a proteção às diferenças e promovam a inclusão social de grupos específicos, que durante séculos permaneceram à margem do acesso às políticas públicas de caráter universal.

A comunidade da Ilha de Tatuoca tem residido no local há cerca de 200 anos e apresentava a 
pesca artesanal como a principal atividade geradora de renda e subsistência. Durante gerações as famílias sobreviveram da pesca artesanal, coleta de mariscos e crustáceos nas regiões vivas dos manguezais e colheita de alguns frutos comuns à região, como manga e caju. Santos e Andrade ${ }^{16}$ afirmam que a comunidade transcende os limites terrestres e sua apropriação do espaço se dá mediante a articulação com aspectos relacionados ao uso, aos símbolos e ao conhecimento sobre as águas, constituindo-se em território marinho. A tradição em questão é intrínseca ao modo de produção e reprodução da vida em um espaço que "extrapola a terra firme e é desenhado pelas águas dos rios e do mar"16.

\section{PERCURSO METODOLÓGICO}

O presente estudo compõe o conjunto de pesquisas que vêm sendo desenvolvidas pelo Laboratório de Saúde, Ambiente e Trabalho (LASAT) do Centro de Pesquisa Aggeu Magalhães $(\mathrm{CPqAM})$ - Fiocruz/PE sobre os impactos socioambientais no território de Suape. Para tanto, foi realizada investigação qualitativa para compreender a percepção e os aspectos subjetivos da população exposta em um território em conflito.

A baía de Suape apresenta, em sua conformação original, a presença das ilhas de Tatuoca e Cocaia, que juntas correspondem a uma área geográfica de 3.600 hectares, banhadas pelas águas provenientes do encontro do mar com três valorosos rios da região: Massagana, Tatuoca e Ipojuca.

A implementação do CIPS na região é responsável por profundas e aceleradas mudanças territoriais, inclusive, atualmente Tatuoca não se categoriza mais enquanto ilha, por apresentar uma via de acesso terrestre construída com a finalidade de ligá-la ao Estaleiro Atlântico Sul (Figuras 1 e 2). Em 2010, o Governo Estadual de Pernambuco aprovou as obras de expansão do CIPS, com a proposta de implantação do Estaleiro Promar, via contratação da empresa Holandesa Van Oord. O resultado desta expansão está sendo a desterritorialização da comunidade tradicional de pescadores artesanais e a profunda descaracterização da Ilha de Tatuoca, considerada Área de Preservação Permanente (APP).

Figura:1- Vista aérea da Ilha de Tatuoca e o estaleiro Atlântico Sul ao fundo (esquerda) e o mesmo estaleiro visto a partir da Ilha de Tatuoca "prainha" (direita).

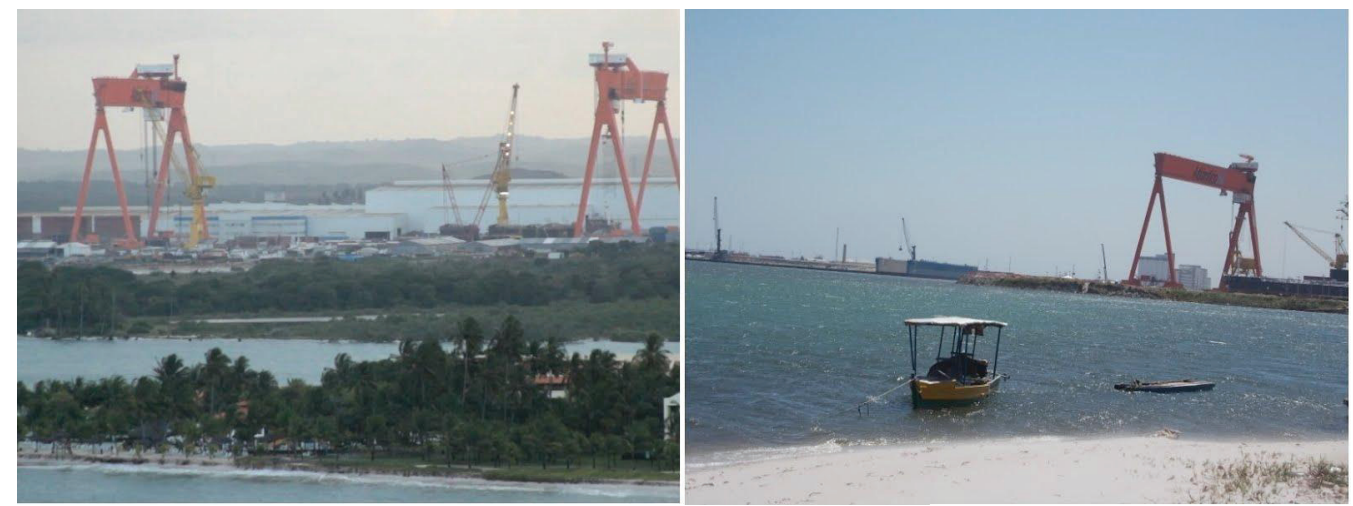

Fonte: Santos, 2013. 
Estima-se que, desde sua última ocupação, a comunidade consolidou-se entre os morros da ilha e o rio Tatuoca, estendendo-se por uma área conhecida, por seus habitantes, como prainha (Figura 1) e ali permanceram durante várias gerações.

Em 2007 o Estaleiro Atlântico Sul começou a ser construído e já na terraplanagem do terreno foram removidas em torno de 20 famílias de Tatuoca. As remoções ocorreram mediante negociação de indenizações, pactuadas individualmente e de valor variado para cada família, fato que colaborou para a dispersão dessa população em territórios periféricos vizinhos. No entanto, não se conhece o local e as condições de nova moradia dessas famílias desterritorializadas, situação que revela a falta de acompanhamento e apoio social às famílias diretamente afetadas do TES pela expansão do CIPS. Em 2011, foram iniciadas as obras de implantação do Estaleiro Promar, que ocupará 97,40 hectares da Ilha de Tatuoca. ${ }^{17}$ Atualmente cerca de 60 famílias remanescentes da ilha estão sendo tensionadas e submetidas a um processo de desterritorialização, semelhante ao ocorrido anteriormente na fase de implantação do Estaleiro Atlântico Sul, em 2007. Entretanto, apenas 48 das 60 famílias são registradas no Relatório de Impacto Ambiental (RIMA) do Estaleiro Promar. O RIMA Promar prevê o remanejamento involuntário dessas famílias para o conjunto habitacional chamado "Nova Tatuoca"17 (Figura 2), que fica na praia de Suape, com casas de dois quartos, sala, banheiro, cozinha e um pequeno quintal. O pequeno espaço destinado para cada família não possibilita o cultivo de alimentos - atividade comunitária consolidada, durante toda a vida na Ilha de Tatuoca, que junto à pesca artesanal constituíam as principais fontes geradoras de renda e subsistência das famílías.

Figura 2 - Sítio com pomares frutíferos que ainda resiste na llha de Tatuoca (esquerda) e as pequenas casas que estão sendo construídas na Nova Tatuoca (direita).

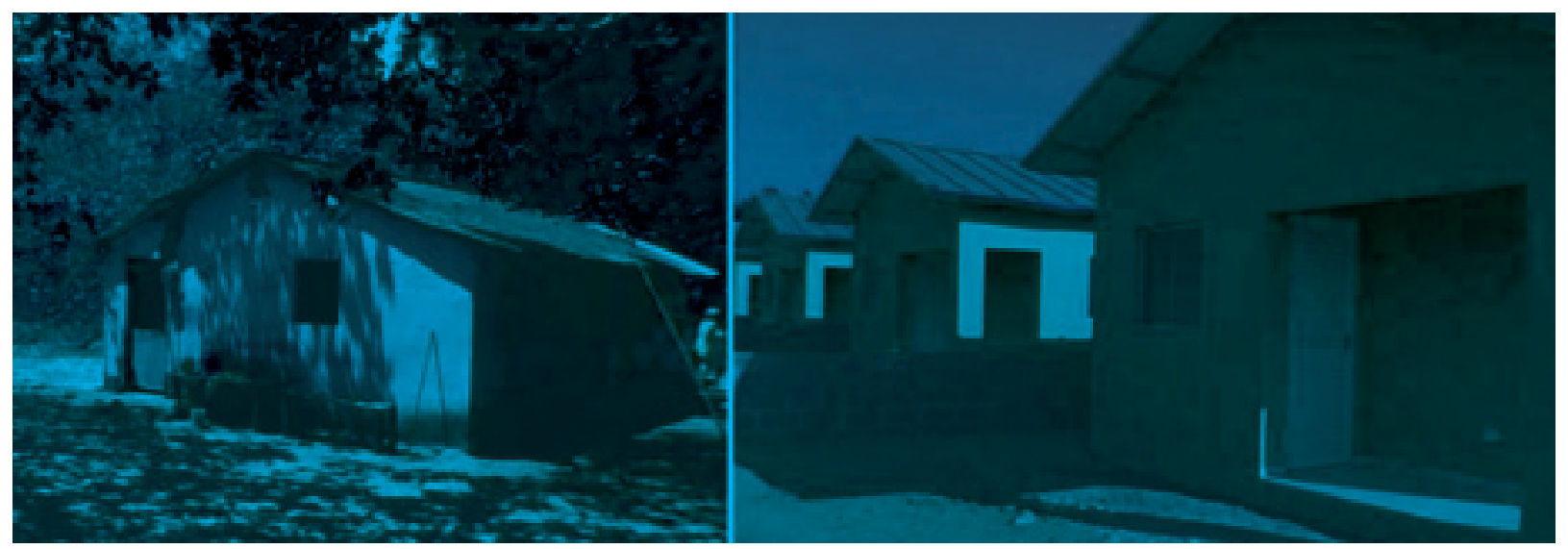

Fonte: Santos, 2013

Os dados foram coletados no período de 2010 a 2013, considerando as seguintes estratégias: (1) visitas ao território, incluindo-se uma expedição científica à Ilha de Tatuoca, para apreensão do contexto local, com registros fotográficos e conversas informais; (2) participação nas reuniões e atividades do Fórum Suape - Espaço Socioambiental, um movimento de luta contra as injustiças ambientais relacionadas ao CIPS; (3) realização de entrevistas com os sujeitos sobre a percepção dos perigos e preocupações decorrentes da implantação da refinaria de petróleo e outros // Tempus, actas de saúde colet, Brasília, 8(2), 69-91, jun, 2014.

ISSN 1982-8829 
empreendimentos previstos no Complexo Industrial.

Foram realizadas 35 entrevistas que compuseram o banco de dados do projeto de pesquisa "Estratégias de Comunicação para a Construção de Territórios Sustentáveis no Contexto da Cadeia Produtiva do Petróleo em Pernambuco - Uma Abordagem de Saúde Ambiental”, aprovado no Comitê de Ética e Pesquisa do CPqAM sob o registro CAEE de $n^{\circ} 135 / 2008$. Todas as entrevistas foram realizadas por uma única pesquisadora, que seguiu um roteiro de perguntas semiestruturado, aplicado a diversos sujeitos do território de Suape: gestores da saúde, gestor de Suape, trabalhadores de Suape, pescadores, moradores de diversas comunidades, representações sindicais e representantes do conselho de saúde, que foram registradas através de recurso audiovisual.

Deste banco foram selecionadas, para o presente estudo, as cinco entrevistas (Quadro 1), realizadas com os moradores da Ilha de Tatuoca (três homens e duas mulheres) que assinaram o Termo de Consentimento Livre Esclarecido.

\section{Quadro 1: Descrição dos sujeitos entrevistados}

\begin{tabular}{|c|c|c|c|c|}
\hline Sujeitos & Atividade Profissional & $\begin{array}{c}\text { Tempo que vive na } \\
\text { ilha }\end{array}$ & Idade & Sexo \\
\hline Sujeito 1 & Pescador & Nativo da ilha & Não informou & Masculino \\
\hline Sujeito 2 & $\begin{array}{c}\text { Pescador e, atualmente, } \\
\text { marinheiro }\end{array}$ & Nativo da ilha & 45 anos & Masculino \\
\hline Sujeito 3 & Pescador & $\begin{array}{c}\text { Nasceu na região e } \\
\text { mora há } 39 \text { anos na ilha }\end{array}$ & 57 anos & Feminino \\
\hline Sujeito 4 & $\begin{array}{c}\text { Pescador e, atualmente, } \\
\text { marinheiro }\end{array}$ & Nativo da ilha & 29 anos & Masculino \\
\hline Sujeito 5 & $\begin{array}{c}\text { Pescadora e, atualmente, } \\
\text { vende almoço para os } \\
\text { trabalhadores do Estaleiro } \\
\text { Atlântico Sul }\end{array}$ & $\begin{array}{c}\text { Nasceu na região, mora } \\
\text { na ilha desde } 2004\end{array}$ & Não informou & Feminino \\
\hline
\end{tabular}

A fase inicial de tratamento dos dados ocorreu mediante a transcrição fiel das entrevistas. Posteriormente, foram realizadas leituras sistemáticas e profundas, para apreender as formações discursivas dos sujeitos sociais, suas experiências acumuladas de vida, relações sociais e sistemas de conhecimento e crenças.

Para análise foram utilizados princípios conceituais da Análise Crítica do Discurso (ACD) e conceitos do campo da saúde e justiça ambiental, abordados no referencial teórico do estudo. A ACD compreende o discurso como uma forma de prática social e por isso deve-se movimentar-se entre o linguístico e o social ${ }^{18}$. Fairclough compreende o discurso como uma forma de prática social que é constitutivo, na medida em que possibilita a definição das estruturas sociais, ao mesmo tempo em que é constituído socialmente. 
Este autor ${ }^{18}$ destaca que a prática discursiva envolve os processos de produção, distribuição e consumo de textos (falados e escritos) através da dimensão da linguagem. A prática social relaciona-se aos conceitos de ideologia e de poder, partindo do conceito de Althusser. Dessa forma, a ideologia é compreendida como significados ou construções da realidade, a partir da construção de "várias dimensões das formas ou sentidos das práticas discursivas e contribuindo para a produção, a reprodução ou a transformação das relações de dominação"19.

Para a ACD, a linguagem é um meio de dominação que serve para legitimar as relações de poder estabelecidas institucionalmente, sendo necessária a descrição das estruturas sociais e a teorização de processos de produção de textos, pois as ideologias estão implícitas nas práticas de grupos ou indivíduos, que são sujeitos históricos e que criam sentidos em sua interação social com textos. Araújo $^{20}$ destaca a importante contribuição da Teoria Social dos Discursos, fonte teórico-conceitual da ACD, que possibilita perceber os discursos existentes e suas disputas pela hegemonia e pelo poder simbólico ao modo semelhante a um mercado, onde os discursos são produzidos, circulam e são consumidos, agregando valor e se transformando continuamente, mediante a ação dos sujeitos e os diversos contextos em que operam, em busca de uma tripla legitimidade.

Portanto, enquanto característica determinante, a qualidade emancipatória da ACD materializase com a investigação das relações entre o discurso e o modo de atuação no mundo e na sociedade, pois permite reconhecer os discursos dos sujeitos sociais para além das estruturas institucionais, favorecendo a desarticulação de tais estruturas. ${ }^{19}$

As entrevistas foram organizadas segundo as seguintes categorias de análise: 1) Percepção sobre o processo de industrialização do CIPS; 2) Impactos ambientais; 3 ) Desterritorialização da população local; 4) Impactos no perfil das atividades de subsistência e geração de renda. Utilizouse como instrumento de apoio o preenchimento de um quadro, que sintetizou trechos de falas dos entrevistados, focando não apenas nas palavras (conteúdo), mas na ideologia por elas representada. A análise fundamentou-se nos aspectos convergentes e divergentes, fazendo emergir os principais resultados e discussões da pesquisa.

A abordagem de análise escolhida trabalha a interface do discurso e as práticas sociais dos sujeitos em estudo. Dessa maneira, a técnica de ACD permite uma análise mais densa da vulneração socioambiental presente no contexto de conflitos do território estudado, com fundamento nas perspectivas críticas das Ciências Sociais.

Os resultados do estudo serão devolvidos para a população em eventos específicos, quanto por meio do Fórum Suape - Espaço Socioambiental.

\section{O DISCURSO DOS ILHÉUS DE TATUOCA}

\section{A percepção sobre o processo de industrialização do CIPS}


A análise da percepção da comunidade de pescadores sobre o processo de industrialização do CIPS permite visualizar ideias centrais que revelam questões relacionadas aos impactos deste processo, como a fragilidade dos investimentos em infraestrutura local, a possibilidade de adesão ao trabalho formal e as mudanças territoriais no local.

Sabe-se que a instalação de grandes processos produtivos exige intensa concentração de mão de obra nos territórios industriais. Em menos de uma década, o quantitativo populacional do TES dobrou e somente no município de Ipojuca, que antes apresentava em torno de 40.000, hoje registra cerca de 81.000 habitantes. ${ }^{21}$ A acentuada migração populacional deve-se ao recrutamento de trabalhadores e mão de obra, advindos de diversos estados. Este fenômeno se faz presente desde a fase de construção e instalação das indústrias até a fase de operação e produção industrial.

É possível perceber com clareza a preocupação, presente nos discursos dos ilhéus, diante do acelerado inchaço populacional da região alinhado à falta de planejamento urbano e aos baixos investimentos em infraestrutura. Além disso, destacam-se os relatos de aumento da violência local, que produzem forte sentimento de insegurança e consequentes impactos nos costumes e dinâmicas da comunidade, essa condição é reforçada conforme observado abaixo:

Tem sua parte boa e também tem sua parte ruim, né. Por que traz pessoas diferente, onde eu moro, muita gente diferente, muita gente estranha. A gente já não tem mais aquela liberdade que tinha antigamente, né. Aqui em Suape, a gente chegava a dormir até de porta aberta, hoje em dia, ninguém faz mais isso. Tem que ter uma precaução, porque tem muita gente estranha no local, ta entendendo? Aí afetou, um pouco assim, nosso jeito de viver um pouco. (Sujeito 2).

Outro aspecto que se expressa na quase totalidade dos discursos é a percepção das alterações territoriais próprias dos processos industriais, como aterro de mangues, construção de rodovias, profusão de maquinários e contêineres. O recorte abaixo expressa a compreensão das significativas mudanças no local, disparadas pelo processo de industrialização da região:

Quando eu vim morar aqui não tinha nada disso, tinha que atravessar de barco, dependia de barco. Ai depois, esse estaleiro foi vindo pra cá e agora tá tudo diferente, mudou tudo. Não tinha nada. (...) Assim, acho de bom porque aparece oportunidade, uma coisa que a gente não tinha nem acesso pra sair, a gente sofria, dependia dos outros pra atravessar (sujeito 5).

Apesar de as entrevistas não pormenorizarem os mecanismos e estratégias de resistência, criados pela comunidade e populações adjacentes, parece existir um sentimento de resignação no discurso da comunidade de pescadores frente a situações e realidades de exploração e injustiça percebidas na experiência vivida. Hipótese fortalecida pelo recorte:

O mundo vive através de quê? de dinheiro, né. Pra controlar tem que ter alguém forte no meio. Mas do jeito que tá... a empresa mundial tá no meio: a Petrobrás. E quem é que para essa obra? Só Deus pode parar essa obra e mais ninguém (Sujeito 4). 
Em contraponto às percepções dos impactos negativos que sobrecarregam a comunidade estudada, a maioria dos sujeitos entrevistados afirma ter ocorrido aumento na possibilidade de trabalho formal. Condição percebida por eles como benéfica, por possibilitar maior aquisição de renda e assegurar direitos trabalhistas, por meio da assinatura da carteira de trabalho, ao reconhecer a melhoria das possibilidades de emprego:

Por uma parte foi bom e por outra é ruim, né? Porque emprego ficou melhor, por enquanto, né... e quanto a parte do meio ambiente: zero!(...) (Sujeito 4).

O recorte de fala do Sujeito 2 reforça essa afirmação quando diz:

E a parte boa foi que surgiu emprego, né, muita gente que, até então, nunca tinha fechado a carteira, hoje em dia, ter um emprego fixo, né, melhorou a expectativa de vida, né. (Sujeito 2).

Entretanto, os Sujeitos 1 e 3 salietam questões relacionadas à precarização das relações de trabalho e à insalubridade dos ambientes laborais nas indústrias, como instabilidade dos vínculos empregatícios, precárias condições de alojamento dos trabalhadores e exposição a riscos de caráter químico.

Vem tanta gente de fora, chega aqui iludido pelo esse emprego, trabalha numa área de risco, que Suape é uma área de risco, trabalha com produtos químico, com gás, etc. e muitas empresa não paga os 30\%. O alojamento que a empresa dava era precário, então houve essas greve, né? (Sujeito 1).

Aqui, agora em 2010, 2008, 2009 foi muito bom aqui, quando começou aí, essa coisa aí, mas quando começou 2010 não deu não, passamos quase 2010 parados aqui dentro.(...) a gente ouviu o homem dizer: "a gente tem que avexar pra tirar esse pessoal daqui de baixo" (Sujeito 3).

É possível observar que a comunidade percebe e sente as fortes alterações territoriais e os consequentes impactos na dinâmica da comunidade, disparados pelos processos industriais instalados na região. No entanto, não se consegue visualizar nos discursos dos sujeitos a relação da atual situação à questões de ordem política, fato que sugere a necessidade da continuidade de estudos na região que desvelem a percepção macropolítica dos moradores e os diferentes mecanismos e estratégias de resistência criados por eles para o enfrentamento das dinâmicas econômicas exploratórias, fundamentadas na coalizão entre as estruturas estatais com as grandes corporações do mercado internacional.

\subsection{A percepção sobre os impactos ambientais}


A segunda categoria de análise compreende o discurso dos entrevistados sobre a percepção relacionada ao impacto ambiental, decorrente das obras de implantação e expansão do CIPS. Reúne e denuncia um conjunto variado de ações exploratórias de consequências ambientais, por vezes, irreversíveis.

Desde que existe Suape existe dragagem, foi largada em área de pesca onde se reproduz a lagosta, onde se reproduz o peixe e outros tipos de espécie de crustáceos que vive ali. Então, com a ambição miserável do dinheiro, o que foi que eles fizeram? "vamo fazer e o pequeno é que se lasque" essa é a palavra: "o pequeno é que se lasque”. O abuso total, e largando o dejeto. (...) A água ficou de uma forma tão suja, ficou quase da cor de sangue vermelhada(...) Aumentou a poluição, aumentou o desmatamento, aumentou a temperatura. Então que dizer: não é mais um lugar 100\% saudável. Hoje eu tenho essa preocupação devido à poluição, que é uma coisa que vai crescer cada dia mais. (...) Porque todas indústrias tão sendo montadas sempre a beira dos rios. Todas indústrias joga dejetos nos rio. É preocupação: esses dejetos são tratados? De que forma são tratados? (Sujeito 1)

As dragagens, discutidas anteriormente, caracterizam-se como uma técnica da engenharia cuja finalidade é remover sedimentos no fundo do mar ou no leito dos rios, para aumentar a profundidade e ensejar o acesso de embarcações de grande porte por vias marinhas. A consequência direta e imediata dessas técnicas é a alteração da salinidade das águas, desnivelamento dos lençóis freáticos e evidente comprometimento do ecossistema e da vida de diversas espécies, como peixes, lagostas e mariscos. ${ }^{9}$ Nos últimos anos, a comunidade encontra-se diante a escassez de água potável, devido ao secamento dos poços artesanais, escavados pelos nativos e moradores locais da Ilha de Tatuoca. Entre as hipóteses que justificam a atual circustância, as dragagens parecem melhor explicar a privação de água já que explosões submarinas alteram a profundidade do mar e dos rios, como também desnivelam os lençóis freáticos.

Além das dragagens, o discurso do Sujeito 1 denuncia ocupação de indústrias poluentes em áreas ribeirinhas e o criminoso despejo de dejetos altamente tóxicos nos leitos dos rios e nas águas do mar. No recorte de fala, ainda revela:

A lagosta foi rejeitada em outros países porque foi achado nela resíduo de ferro" (Sujeito 1).

A ocorrência de fatos desta natureza revela a falta de fiscalização e regulação do Estado diante de indústrias predatórias e a irresponsabilidade sanitária das instituições gestoras da saúde pública local.

O discurso dos sujeitos apresentou outras ações fundamentadas na insustentabilidade ambiental, como vastas áreas de desmatamento e aterro de manguezais, impactando bruscamente na 
reprodução e na densidade de inúmeras espécies de crustáceos nativas dos mangues, como siri, aratu e caranguejo, condição expressa no discurso:

Isso aí tudo era mata, menino. Acabou-se tudinho. (Sujeito 3)

Pronto, essa área que você tá vendo do complexo aqui, tudo era mangue, tudo era mangue. Se pegava guaiamum e do muito, garanguejo. Então, todo mundo, área da pesca, tinha sustentabilidade aqui. Área de marisco, que aqui era uma grande reprodução de marisco, acabo, acabo (Sujeito 2).

Antes o meio ambiente não era 100\%, mas vamos botar uns 99\%. Hoje vamos botar uns $40 \%$, em média. É, poluição mais, dematamento mais ainda, os peixes desapareceu, crustáceo desparecendo, e cada vez vai assim (...) (Sujeito 4)

Não tinha nada, nada. Aí quando foi em dois mil e cinco, eu ainda tava grávida, foi que veio uns povo, assim, com as máquinas, aí foi derrubando o mangue, tudinho (...) (Sujeito 5)

As discussões e estudos sobre as alterações de alto impacto ambiental na área de estudo são de fundamental importância, devido inclusive à Ilha de Tatuoca ser uma área de manguezal, considerada Aréa de Preservação Permanente que, de acordo com o novo Código Florestal, instituído pela Lei no12.651/12, constitui-se em:

Área de Preservação Permanente - APP: área protegida, coberta ou não por vegetação nativa, com a função ambiental de preservar os recursos hídricos, a paisagem, a estabilidade geológica e a biodiversidade, facilitar o fluxo gênico de fauna e flora, proteger o solo e assegurar o bem-estar das populações humanas. ${ }^{22}$

O novo Código Florestal ainda dispõe sobre as condições de intervenção e/ou supressão de vegetação nativa em APP, sendo essas admitidas somente nas hipóteses de baixo impacto ambiental, previstas nesta Lei, ou de utilidade pública de interesse social ${ }^{22}$, categoria em que o CIPS se enquadra por ter legitimidade frente a sua importância econômica para o estado. Dessa forma,

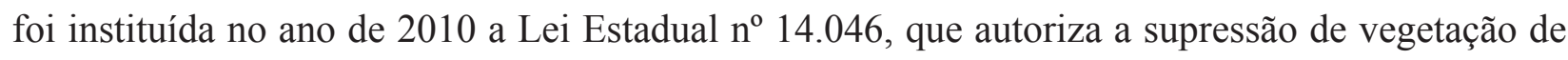
preservação permanente para a expansão do CIPS. Em memorial disposto nessa Lei é possível a identificação das áreas destinadas à ampliação e modernização do Porto de Suape, na qual a Ilha de Tatuoca se encontra localizada entre as propriedades Engenho Massangana - Gleba 1, Ilha dos Barreiros, Ilha da Cana e Ilha de Tatuoca, abrangendo 298,5062 hectares de área de manguezal. ${ }^{23}$

Porto $^{5}$ reconhece a consolidação do senso comum que entende o desenvolvimento dominante, caracterizado pela busca permanente do crescimento fundamentado em atividades extrativistas, 
como algo de qualidade insustentável por destinar-se ao esgotamento dos recursos naturais. $\mathrm{O}$ autor $^{5}$ ainda tece comentários de mesmo teor:

Infelizmente, a opinião pública não vai além dessa constatação e não percebe que o espaço perde, então, as suas características ecosssistêmicas - diversidade, complementariedade, resiliência, renovação - e se torna um espaço indefinido, mero suporte para as atividades econômicas e as infraestruturais. ${ }^{5}$

A análise da categoria da percepção dos ilhéus sobre os impactos ambientais permite observar que as práticas comunitárias de pesca artesanal, como cultura e fonte de subsistência, possuem relações harmoniosas de usufruto dos recursos naturais e se vinculam aos princípios da sustentabilidade e da conservação dos biomas.

Antigamente a pescaria era mais artesanal, né, no caso da lagosta mesmo, a gente pescava com covo, sabe o que é covo, né? Que é aquela armadilha de madeira, coberta com tela, onde a gente só pescava a lagosta daquele jeito. Hoje em dia, mudou...existem muitos mergulhadores pescando com compressor e redes, onde pega todo tamanho e todo tipo de lagosta, né...Então, houve mais retirada de lagosta do mar e pouco tempo de espera para que ela se reproduzisse, né. (Sujeito 2).

Quando vim morar aqui era tudo, era a coisa mais linda, a árvore e tudo, tanto pé de fruta. Pronto, hoje não tem quase nada. Pé de caju, mangaba, que muita gente que mora em Tatuoca sobrevive disso, tirando caju, mangaba. Hoje não tem mais. Porque destrói tudo. Derruba pé de coqueiro, mangaba, cajueiro, tudo, tudo, tudo (Sujeito 5).

O discurso está inserido em uma esfera consciente da progressão e irreversibilidade dos impactos ambientais. E que os conflitos derivados dessa realidade complexa manifestam-se de forma concreta e afetam diretamente a saúde humana e o ambiente, como a intoxicação por metais pesados das espécies marinhas e humanas.

\section{A percepção sobre o processo de desterritorialização}

Ao analisar o processo de desterritorialização da comunidade de pescadores artesanais da Ilha de Tatuoca é imprescindível atentar para o fato de não ser somente um processo de deslocamento geográfico, mas um desafio econômico e cultural que se estabelece e se impõe às famílias ali consolidadas. O discurso analisado sob esta dimensão oferece argumentos que fortalecem a premissa de que o território é para a comunidade fonte de produção e reprodução da vida e também sua referência histórica e sua identidade. Isso se constata claramente quando observamos o recorte de fala do Sujeito 4, que diz: "a gente vive sobre a água". Nesse cenário, a tradição ganha um sentido ampliado e sutil, pois passa a contemplar a preservação de conhecimentos ancestrais, adquiridos através da experiência empírica, e sentimentos de pertencimento ao lugar onde se vive 
e se reconhece.

Até agora saiu uma parte da ilha, a outra parte continua na ilha.(...) Ah, eu acho ruim, né. Porque o pessoal que mora aqui jamais vai se adaptar na cidade. O pessoal vive da pesca, aí o cara vai morar na cidade já é outro tipo de vida, né, muito diferente (Sujeito 2).

Expressa a percepção de que o deslocamento para outro lugar implica, necessariamente, em bruscas mudanças no modo se viver e perda do sentimento de pertencimento ao lugar onde habita:

Eu to muito acostumada aqui, já morei lá fora, mas não me acostumei, voltei, vim morar aqui de novo(...) (Sujeito 3).

(...) eu amo esse lugar, eu adoro. Ai se for por mim, eu nunca queria sair (Sujeito 5).

As falas revelam um forte vínculo afetivo e simbólico dos pescadores com o lugar em que se habita, fato que fortalece a construção de uma identidade. Além disso, as falas demonstram um acúmulo de conhecimento tradicional compartilhado coletivamente pelos nativos e locais da ilha e formas próprias de organização e produção de vida no local, que se torna evidente no relato do Sujeito 1, que diz:

Porque uma pessoa que vive da agricultura, vive da pesca, ainda que compre um terreno, não aqui, em outro lugar, não tem condições de construir. (...) Então é uma falta de respeito ao povo da ilha e aos pescadores (...) Se for tirado isso aqui, a gente vai perder vários pontos localizados de área de pesca (Sujeito5).

Outro aspecto relevante a ser discutido é o relato de quatro dos cinco entrevistados de que a condução do processo de remanejamento involuntário dos ilhéus acontece de maneira violenta, sem o norte de políticas públicas de proteção e sem critérios. A quase totalidade dos discursos revela a oferta de indenizações que não asseguram condições dignas de moradia, expondo as famílias a uma condição de insegurança e precariedade. Além disso, as indenizações são ofertadas mediante negociações individuais, com grandes flutuações entre as famílias e, por vezes, ameaçadoras:

A oferta maior pra eles até hoje foi quarenta mil reais, eu garanto que não compra um terreno pra viver, imagina pra construir. (Sujeito 1).

O governo de Estado manda o dinheiro pra tirar o povo daqui, agora por aqui ninguem recebe ele não. O que é que a pessoa vai fazer com 20 mil, 30 mil lá fora? Vai fazer o que lá fora? Pra construir casa, comprar casa e tudo, vai fazer o que lá? Nada. Nem ponte, nem viaduto tem mais pra ninguem morar (Sujeito 3).

Tem gente aqui que avaliou a casa por 800 reais. E a pessoa vai fazer o que com // Tempus, actas de saúde colet, Brasília, 8(2), 69-91, jun, 2014. 
800 reias? Dizem que vai entrar com integração de posse, é para a pessoa intimidar e perder, né... que antigamente, antes quando vei esse Estaleiro aí, saiu 4 famílias... uma saiu no valor de 5 mil reais, outra de 9 mil (..) Ai, hoje moram numa favela. A gente quer sair com uma casa, num lugar que a gente quer morar(...) É isso que a gente pensa aqui, Suape tá daquele jeito, né, num quer pagar o certo e começa a mexer os pauzinho dela, já que os pau da gente é mais pequeno, mais curto do que os dela, né (Sujeito 4).

Oferecendo mixaria, ameaçando derrubar a casa com tudo dentro. Foi. Aí muitos teve medo, assim, né, de perder o pouco que tinha né? Foi de repente, foi muito rápido que isso aconteceu (Sujeito 5).

Em relação ao direito à terra dos ilhéus, o que predomina, por gerações, é o contrato (verbal) de alienação que coloca a ilha sob dois tipos de domínio: o domínio eminente, ou direto do dono, e o domínio útil, ou indireto, dos moradores. ${ }^{24}$

Nesse contexto, a possibilidade de ser efetuado um processo de reterritorialização dessas famílias restringe-se, limitando-se ao mero processo de remanejamento espacial. É por esse mecanismo, comumente utilizado pela força da reprodução do capital, que se intensifica o fomento às desigualdades. Outro produto dessa dinâmica discriminatória é a segregação espacial, que isola e concentra as populações vulneradas nas periferias dos grandes pólos urbanos industriais. ${ }^{25}$

\section{A percepção sobre os impactos no perfil das atividades de subsistência e geração de renda}

A análise desta categoria proporciona a possibilidade de penetrar no cerne do problema deste estudo, pois é pelos impactos no perfil das atividades de subsistência e de geração de renda que alçaremos a clareza da transcendência da vulneração socioambiental imposta pela expansão do CIPS na região estudada. É evidente a consolidação da atividade pesqueira como principal fonte de renda e subsistência das famílias da ilha. O discurso dos sujeitos, não somente nesta categoria como em todas as anteriores, destaca o drama social vivido por esta comunidade, decorrente da inviabilização da atividade da pesca artesanal.

Eu vivo da pesca desde os 14 anos. Eu sou nativo daqui, toda minha família é descendente de pescador e até hoje nós vivemos, tiramos nosso sustento da atividade da pesca. Coisa que hoje tá praticamente impossível, devido à degradação ambiental que foi feita por Suape de forma irresponsável.(...) Legitimamente na cultura da pesca que nós fomos criados (Sujeito 1).

Aí, já pesquei muito, peguei muito marisco, muito siri, caranguejo, até peixe mesmo. Agora não tem mais não, mas tinha muito, já peguei muito peixe, foi com que criava meus filhos aqui dentro (Sujeito 3). 
Esse povo sobrevivia aqui pescando, ai pescava e vendia aqui, e fazia as compras. Antes sobrevivia de quê? De pegar aratu, pegar caranguejo, pegar siri, pra sobreviver. É a semana todinha, de segunda a sexta. Aqui ninguém trabalhava em firma não. (Sujeito 5).

O discurso dos moradores faz emergir a complexidade dos conflitos enfrentados, pois a atividade da pesca, além de ser a fonte basilar de subsistência e geração de renda, também é crença, costume e arte. Ramalho, ao estudar a estética marítima pesqueira, comenta:

Apesar de se situarem nesse contexto adverso, um fato me chamou atenção: os pescadores categorizaram seu saber-fazer pesqueiro de belo, reunindo nele atributos como resistência, perfeição, aprazível e humanização da natureza, enquanto um sentir compartilhado. ${ }^{26}$

Assim, a pesca artesanal se configura como elemento de força na organização social da comunidade e metaforicamente, no âmbito cultural, pode ser comparada à uma rede de pesca tecida pelas interrelações dos sujeitos e seus saberes. Outro aspecto relevante da atividade pesqueira é o atributo de aprazível, ou seja, através da atividade laboral é possível o alcance do prazer. O entrevistado 2 exprime:

Nas minhas horas vagas eu pesco, mas não profissionalmente, eu pesco por divertimento, né. (Sujeito2).

Mesmo que atualmente a pesca não seja a principal fonte geradora de renda, o ilhéu continua a pescar como meio de alcançe do prazer e da diversão. Em vista dessa estreita relação com o elemento aquático, no Brasil algumas populações são chamadas de "povos das águas". Outra qualidade que se sobressai no estudo desses povos e particularmente na comunidade da Ilha de Tatuoca é a organicidade da autonomia presente na geração de renda e subsistência por meio da pesca artesanal.

Isso é uma mediação social prioritária para justificar o trabalho como território da arte e construtor do sentimento de homens libertos, opondo-se aos espaços esterilizadores de uma estética da existência que inibem o caráter do aprazível, do belo e da autonomia irmanados à esfera produtiva. $^{26}$

$\mathrm{O}$ aspecto da autonomia pode ser melhor compreendido como a qualidade de homem não cativo do trabalho. Por isso, oferece a potência aos trabalhadores das águas de vir a ser "homens libertos", diante do contexto global do mundo do trabalho e do capital. Ramalho ${ }^{26}$ afirma: "O trabalho gerador do aprazível acompanha a vida não cativa do pescador. O belo é a satisfação pela arte, que é a própria realização das objetivações concretas que permitem ao pescador reproduzir-se".

O entrevistado 1 exprime a seguinte indagação: "Eles querem tirar o pescador da pesca pra 
trabalhar em firma de ajudante, né? ”. É possível sentir que há, para alguns sujeitos, a percepção de que a mudança no perfil da atividade laboral os condena à condição de subordinação e tolhimento do aspecto criador e livre do homem.

A fim de propiciar uma melhor compreensão sobre a percepção dos ilhéus relacionada às oportunidades de empregos no CIPS, bem como às qualidades dos vínculos trabalhistas, reúne-se a seguir as ideias centrais, referentes à questão abordada pelos 5 Sujeitos entrevistados:

Quando você vai fazer três mês pra vencer a experiência eles mandam embora. E muitos pescador são analfabeto e analfabeto não tem emprego fixo. Muita coisa em Suape é ilusão, né? (Sujeito 1).

Muita gente se adapta, entendeu? E muitos não conseguem se adaptar, entram, passam um tempo e saem, mas a maioria fica. (Sujeito 2).

Os que vivem aqui vive trabalhando, logo antes tavam tudo trabalhando aqui no estaleiro. Mas foi tempo que cortou muita gente aí, aí os meninos saíram. (Sujeito 3).

Essas empresas que tão chegando, dão emprego temporário, né. Por que muitas empresas, o que? Elas pega termina o contrato e contrata gente de fora, só bota os da área pra fazer mídia, pra dizer que empregou. Aí depois demite e diz que foi um mal funcionário, né e faz o que lá sabe fazer melhor. O estaleiro começou a pegar bastante gente e agora ta demitindo a maioria. (Sujeito 4).

Aí depois que esse estaleiro veio pra cá foi muita melhora, né, porque deu muitos emprego de carteira fichada (Sujeito 5).

Apesar disso, a quase totalidade dos sujeitos percebe a possibilidade de emprego formal como a principal vantagem da chegada das empresas e indústrias na região. No entanto, todos os entrevistados são conscientes da instabilidade dos vínculos empregatícios e alguns relatam se sentirem alvos de estratégias midiáticas e mercadológicas, contrariando o discurso exclusivamente desenvolvimentista assumido pela mídia impressa em Pernambuco. ${ }^{8}$

\section{CONSIDERAÇÕES FINAIS}

Diante da impossibilidade e do desejo de não esgotar a discussão desse problema, nem tampouco finalizar traçando soluções fechadas para sistemas abertos, reafirmaremos aqui a fração de conhecimento alcançada por este estudo.

O processo de industrialização global e contemporâneo atinge os moradores da Ilha de Tatuoca em variadas esferas de suas vidas: na sua cultura, crença, identidade, saúde, moradia, segurança e também em seu trabalho e ambiente. Porto ${ }^{5}$ afirma existir dois grandes grupos responsáveis por 
situações de injustiças ambientais: o primeiro se refere às atividades econômicas exploratórias e seus agentes, que sobrecarregam territórios e populações e interferem diretamente ou indiretamente em suas dinâmicas e modos de vida. O segundo está associado à atuação ou omissão do Estado, que apresenta debilidade em seus processos regulatórios e também estabelece coalizões com grandes coorporações do setor econômico produtivo.

Neste contexto, $\mathrm{Schramm}^{4}$ discute o fortalecimento da biotética da proteção como alternativa de resistência aos contextos adversos de conflitos de interesses e valores, dentre os quais as estruturas de poder e dominação se manifestam e produzem situações de vulneração. Para o autor ${ }^{4}$, existe o dever do Estado em assegurar direitos básicos e, por isso, mesmo em um contexto de Estado mínimo, o mesmo não pode se esquivar de proteger seus cidadãos. No entanto, neste caso a comunidade da Ilha de Tatuoca segue enfrentando conflitos de variadas dimensões e cotidianamente sofrendo situações de violência, discriminação, exploração e abandono. Esta é uma população que sofre os impactos e os traumas das intervenções ambientais decorrentes dos empreendimentos no seu território, portanto, é uma população vulnerada ${ }^{4}$, que vivencia um processo de desterritorialização imposto por um modelo de desenvolvimento que sequer lhes garante emprego, renda e reprodução social.

Conforme assinala Rattner ${ }^{27}$, esse modelo de desenvolvimento, apoiado em uma política liberal orientada para o mercado, não reduzirá os níveis de pobreza, exclusão e desespero. Contribuem para o aumento da "desigualdade de distribuição de riqueza, da informação e de acesso a oportunidades de educação e emprego". ${ }^{27}$

A perspectiva ampliada da saúde, fundamentada no processo de determinação social do processo saúde-doença, considera esse contexto austero dos grandes processos produtivos um cenário no qual ocorre claramente o acúmulo de risco e danos na história e na saúde das populações expostas. Alguns autores $8,9,21,28$ afirmam perceber mudanças epidemiológicas e sociais nesses locais de implantação e operação de grandes cadeias produtivas, como aumento da violência, incidência de doenças, exploração sexual e infantil e sofrimento psicossocial.

Contudo, a estrutura dual e sectarizada que fundamenta as dinâmicas no mundo do capital separa a mente do corpo, o homem da natureza e o indivíduo do coletivo. Dessa forma, em prol de um crescimento irracional e insustentável da economia mundial, podam-se a liberdade e o poder autopoiético das pessoas. Maturana e Varela ${ }^{29}$ explicam a organização do ser vivo a partir do conceito de autopoiese que se define "como um operar circular fechado de produção de componentes que produziam a própria rede de relações de componentes que os gerava", dessa forma, é possível perceber o homem enquanto criador e criação. A natureza autopoiética possibilita o devir da realidade e, portanto, o devir dos paradigmas opressores e dos seres cativos. 


\section{REFERÊNCIAS}

1. Buss, PM. Promoção da saúde e qualidade de vida. Rev. Ciência \& Saúde Coletiva[internet]. 2000 [acessado em 10 de mar. de 2014] 5(1):163-177. Disponível em: http://www.scielo.br/pdf/ csc/v5n1/7087.pdf http://www.scielo.br/pdf/csc/v5n1/7087.pdf

2. Almeida Filho N. A problemática teórica da determinação social da saúde. in: Nogueira RP, editor. Determinação Social da Saúde e a Reforma Sanitátria. [internet].Rio de Janeiro: CEBES; 2010. p.13-36. Disponível: http://www.cebes.org.br/media/File/Determinacao.pdfhttp://www. cebes.org.br/media/File/Determinacao.pdf

3. Santos BS. Para além do Pensamento Abissal: Das linhas globais a uma ecologia de saberes. Rev.Crítica de Ciências Sociais [internet].2007[acessado em 15 de mar. de 2014] 78: 3-46. Disponível em: http://www.ces.uc.pt/myces/UserFiles/livros/147_Para\%20alem\%20do\%20 pensamento\%20abissal_RCCS78.pdf

4. Schramm FR. Vulnerabilidade, vulneração, saúde pública e bioética da proteção: análise conceitual e aplicação. In: Ética e pesquisa com populações vulneráveis., Rio de Janeiro: Ed. EdUFRJ; 2012.

5. Porto MF, Pacheco T, Leroy JP. Injustiça Ambiental e Saúde no Brasil: O Mapa de Conflitos. Rio de Janeiro: Editora FIOCRUZ; 2013.

6. Costa júnior, FJA. Novo desenvolvimentismo, governo lula e o programa de aceleração do crescimento: uma análise crítica [Dissertação]. Ceará: Universidade Federal do Ceará; 2003.

7. Pernambuco. Decreto $\mathrm{n}^{\mathrm{o}}$ 37-160, 23 de setembro de 2011, Institui o Plano DiretorSuape 2030 e dá outras providências. Pernambuco, 23 set. 2011. [acessado em 05 de abr.2014]; Disponível em: http://www.inteligenciaambiental.com.br/sila/pdf/mdecexepe37160-11.pdfhttp:// www.inteligenciaambiental.com.br/sila/pdf/mdecexepe37160-11.pdf

8. Santos, MOS. Análise Crítica do Discurso da Mídia Impressa sobre a Saúde e o Ambiente no Contexto da Instalação da Refinaria de Petróleo em Suape-PE [Dissertação]. Pernambuco: Centro de Pesquisas Aggeu Magalhães, Fundação Oswaldo Cruz; 2011.

9. Gurgel AM, Medeiros ACLV, Alves, PC, Silva JM, Gurgel, IGD, Augusto LGS. Framework dos cenários de risco no contexto da implantação de uma refinaria de petróleo em Pernambuco. Rev. Ciência \& Saúde Coletiva [internet]. 2009 [acessado em 20 de mar. de 2014] 14(6): 2027-2038. Disponível: http://www.scielo.br/pdf/csc/v14n6/10.pdfhttp://www.scielo.br/pdf/csc/v14n6/10.pdf

10. Porto MF, Finamore R. Riscos, saúde e justiça ambiental: o protagonismo das populações atingidas na produção de conhecimento. Rev. Ciência \& Saúde Coletiva. [internet]. 2012[acessado 
em 20 de mar. de 2014] 17(6):1493-1501.Disponível em: http://www.scielo.br/pdf/csc/v17n6/ v17n6a13.pdf http://www.scielo.br/pdf/csc/v17n6/v17n6a13.pdf

11. Porto, MF. Uma Ecologia Política dos Riscos: princípios para integrarmos o local e o local na promoção da saúde e da justiça ambiental. 1 ed. Rio de janeiro: Editora Fiocruz; 2007.

12. Haesbaert R. Território e multiterritorialidade: um debate. Rev. GEOgraphia [Internet]. 2007[acessado em 04 de mar. de 2014] Ano IX(17):19-46. Disponível em:http://www.uff.br/ geographia/ojs/index.php/geographia/article/view/213/205

13. Chelotti, MC. Reterritorialização e Identidade Territorial. Rev. Sociedade \& Natureza[internet].2010 [acessado em 04 de mar. de 2014] 22 (1): 165-180. Disponível em: http:// www.scielo.br/pdf/sn/v22n1/12.pdf http://www.scielo.br/pdf/sn/v22n1/12.pdf

14. Brasil. Decreto $n^{0}$ 6040, de 7 de fevereiro de 2007, Institui a Política Nacional de Desenvolvimento Sustentável dos Povos e Comunidades Tradicionais. Diário Oficial [da República Federativa do Brasil]. Brasília, 8 de fev. de 2007.

15. Silva, MO. Saindo da invisibilidade - a política nacional de povos e comunidades. Rev. Inclusão Social[internet]. 2007 [acessado em 03 de jun. de 2014] 2(2):7-9. Disponível em: http:// revista.ibict.br/inclusão/indx.php/inclusão/article/viewFile/91/98

16. Santos, JO. Andrade, MO. Dossiê: Religião, biodiversidade e território - Artigo: Festa da Ouriçada e devoção a Santa Luzia na praia de Suape - PE. Horizonte[internet]. 2013 [acessado em 10 de mar. de 2014] 11(30):545-571. Disponível em: http//periodicos.pucminas.br/index.php/ horizonte/article/view/P.2175-5841.2013v11n30p545/5365

17. Moraes \& Alboquerque Advogados e consultores. Estudo de Impacto Ambiental Complementar - EIAC do Estaleiro PROMAR S.A. Volume 1-Volume 2 do EIA+RIMA; 19 de nov. de 2010. 7742/2010. Disponível em: http://pt.slideshare.net/vfalcao/rima-promar-211110\#http:// pt.slideshare.net/vfalcao/rima-promar-211110

18. Fairclough N. Discurso e mudança social. Brasília-DF: Universidade de Brasília, 2001

19. Magalhães, CM (org). 2001. Reflexões sobre Análise Crítica do Discurso, Belo Horizonte: Faculdade de Letras, UFMG.

20. ARAÚJO, I. S. Mercado Simbólico: interlocução, luta, poder-Um modelo de comunicação para políticas públicas. 2002. Tese (Doutorado) - Escola de Comunicação, Universidade Federal do Rio de Janeiro, Rio de Janeiro, 2002.

21. Peruzzo JF, Silva MG, Soares RC, Amaral AS. Relatório Final: Diálogos para o 
Desenvolvimento Social em Suape. Grupo de pesquisa: Diálogos Suape. Universidade Federal de Pernambuco, dez de 2013.

22. http://www.planalto.gov.br/ccivil_03/_ato2011-2014/2012/lei/112651.htm

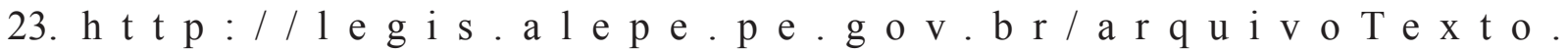
aspx?tiponorma $=1 \&$ numero $=14046 \&$ complemento $=0 \& a n o=2010 \&$ tipo $=$ TEXTOORIGINAL

24. De almeida, MMA. Uma história do litoral Pernambucano e o porto dos caminhos sinuosos. V Colóquio de História: pespesctivas históricas, historiografia, pesqurvoisas e patrimônio; 2011[acessado em 28 de mar. de 2014]; Pernambuco. Disponível em: http:/www.unicap.br/ coloquiodehistoria/wp-content/uploads/2013/11/5Col-p.1331-1344.pdf.

25. SANTOS, M. Economia Espacial: Críticas e Alternativas. $2^{\circ}$ Ed. São Paulo: USP, 2007.

26. Ramalho WN. Estética marítima pesqueira: perfeição, resistência e humanização do mar. Rev. Ambiente \& Sociedade [internet]. 2010 [acessado em 6 de abr. de 2014] XIII(1): 95-110. Disponível em: http://www.scielo.br/pdf/asoc/v13n1/v13n1a07.pdf

27. RATTNER, H. Sobre o desenvolvimento sustentável. Mercosul e ALCA: o futuro incerto dos países sul-americanos. São Paulo: EdUSP, 2002. 228p.

28. Marques, KKD. MORADORES INVISÍVEIS: O SOFRIMENTO SOCIAL DOS MORADORES DA ILHA DE TATUOCA - IPOJUCA - PE - EM SEU PROCESSO DE DESTERRITORIALIZAÇÃO [Dissertação]. Pernambuco: Centro de Pesquisas Aggeu Magalhães, Fundação Oswaldo Cruz; 2011.

29. Maturana HR, Varela FG. A arvore do conhecimento: as bases biológicas do entendimento humano. São Paulo: PSY; 1995.

Artigo apresentado em 07/04/14

Artigo aprovado em 23/06/14

Artigo publicado no sistema em 29/06/14 